\title{
0200 THE EFFECTIVENESS AND COST-SAVINGS OF FIRST EYE CATARACT SURGERY IN REDUCING CRASH RISK: A POPULATION BASED STUDY
}

L Meuleners, ${ }^{*}$ D Hendrie, J Ng, J Semmens Correspondence: Curtin University of Technology, GPO Box U 1987, Perth 6845, Australia

\subsection{6/ip.2010.029215.200}

The present study examined the effectiveness of cataract surgery in terms of crash risk and associated costs on drivers aged 60 and older at a population level. A retrospective before and after comparison of all Police reported crashes which included fatal, hospitalisation, injury and property damage only (PDO) crashes, for patients who had undergone cataract surgery in the first eye was undertaken using linked data from the Western Australian Data Linkage System. An economic analysis by the type of crash was also undertaken on the cost savings from cataract surgery as a result of reducing crash risk for this group. Between 1997 and 2006, there were 27827 patients in Western Australian who underwent cataract surgery in one eye only. Of this cohort, 1715 patients were involved in 1762 Police reported crash events, either 1 year before ( $n=941$ crashes) or 1 year after cataract surgery ( $n=821$ crashes). The results of the Poisson Generalised Estimated Equation analysis found a significant reduction of $13 \%(p<0.001)$ in all Police reported crashes frequency after accounting for all relevant covariates. The cost savings from this reduction in crashes amounted to $\$ 4.3$ million. The results of this study have provided some useful findings relating to the effectiveness and cost saving of first eye cataract surgery in reducing crash involvement for older drivers that will be useful both in future policy development and guide future research in this field. 